\title{
Terapi Reperfusi pada Infark Miokard dengan ST-Elevasi
}

\author{
Hana A. Bambari, ${ }^{1}$ Agnes L. Panda, ${ }^{2}$ Victor F. F. Joseph ${ }^{2}$
}

\author{
${ }^{1}$ Program Studi Pendidikan Dokter Fakultas Kedokteran Universitas Sam Ratulangi, Manado, \\ Indonesia \\ ${ }^{2}$ Bagian Ilmu Penyakit Jantung dan Pembuluh Darah Fakultas Kedokteran Universitas Sam \\ Ratulangi, Manado, Indonesia \\ Email: hanabambari@gmail.com
}

\begin{abstract}
Myocardial infarction is classified into ST-segment elevation myocardial infarction (STEMI) and Non-ST-segment elevation myocardial infarction (NSTEMI). STEMI patient is considered for a reperfusion therapy, consisting of percutaneous coronary intervention (PCI), fibrinolytic therapy, and coronary artery bypass grafting (CABG). This study was aimed to determine the effectiveness of reperfusion therapy in STEMI patients. This was a literature review study. The results described the effectiveness of reperfusion therapy in terms of the time action, as follows: effective PCI if $<120$ minutes, fibrinolytic therapy $<90$ minutes, and CABG within four to 30 days after angiography. In case of revascularization with PCI there was a decrease in mortality and complications of reinfarction, major bleeding, and stroke. There was a reduction in complications of cardiogenic shock with fibrinolytic therapy when given within the first 60 minutes of symptom onset. Fibrin-spesific fibrinolytics (accelerated infusion alteplase, tenecplase, and reteplase) were the most effective regimen associated with reduced mortality. CABG procedure is recommended in coronary anatomical conditions that was not suitable for PCI and several other indications; although the complications were high but the survival of 30 days and one year was very good. In conclusion, PCI is the first line choice and effective if performed less than the first 120 minutes. Fibrinolytics are effective if they are administered during the first 60 minutes in case the PCI is not performed. Moreover, CABG is recommended in anatomical coronary condition that is not suitable for PCI and other indications.
\end{abstract}

Keywords: reperfusion therapy, acute myocardial infarction, STEMI

\begin{abstract}
Abstrak: Infark miokard diklasifikasikan atas ST-segment elevation myocardial infarction (STEMI) dan Non-ST-segment elevation myocardial infarction (NSTEMI). Pada pasien STEMI diper-timbangkan untuk dilakukan terapi reperfusi yang terdiri dari percutaneous coronary intervention (PCI), terapi fibribolitik, dan coronary artery bypass grafting (CABG). Penelitian ini bertujuan untuk mengetahui efektivitas terapi reperfusi pada pasien STEMI. Jenis penelitian ialah literature review. Hasil penelitian ini menjelaskan efektivitas terapi reperfusi ditinjau dari waktu tindakan. Tindakan PCI efektif dilakukan $<120$ menit, terapi fibrinolitik $<90$ menit, dan CABG dalam empat hingga 30 hari setelah angiografi. Pada kasus revaskularisasi dengan tindakan PCI terdapat penurunan mortalitas dan komplikasi reinfark, perdarahan mayor, dan stroke. Terdapat penurunan komplikasi syok kardiogenik pada terapi fibrinolitik bila diberikan dalam 60 menit pertama setelah onset gejala. Fibrin-spesific fibrinolytics (accelerated infusion alteplase, tenecplase, dan reteplase) merupakan regimen yang paling efektif dikaitkan dengan penurunan mortalitas. Tindakan CABG direko-mendasikan pada kondisi anatomi koroner yang tidak sesuai untuk PCI dan beberapa indikasi lain; meskipun komplikasi tinggi namun kelangsungan hidup 30 hari dan satu tahun sangat baik. Simpulan penelitian ini ialah tindakan PCI merupakan pilihan lini pertama dan efektif diberikan dalam waktu $<120$ menit. Fibrinolitik efektif diberikan dalam 60 menit pertama bila PCI tidak dapat dilakukan sedangkan tindakan CABG direkomendasikan pada kondisi anatomi koroner yang tidak sesuai untuk PCI dan beberapa indikasi lain.
\end{abstract}

Kata kunci: terapi reperfusi, infark miokard akut, STEMI 


\section{PENDAHULUAN}

Global Health Estimate (GHE) tahun 2016 mencatat bahwa kedudukan ischaemic heart disease atau coronary heart disease (CHD) menempati posisi pertama dengan angka kematian mencapai 126 per 100,000 populasi atau diperkirakan $16,6 \%$. Data di Amerika Serikat pada tahun 2013, pasien acute coronary sindrome (ACS) yang datang ke rumah sakit dengan ST-elevation myocardial infarction (STEMI) diperkirakan sekitar 38\% dari 116,793 pasien dan memiliki angka persentase yang berbeda berdasarkan jenis kelamin yakni: $57 \%$ terjadi pada pria dan $43 \%$ terjadi pada wanita. ${ }^{1,2}$

Angka kejadian STEMI tetap menjadi penyebab utama yang memengaruhi morbiditas dan mortalitas di dunia. Namun berdasarkan beberapa penelitian yang terus dikembangkan, terdapat penurunan angka mortalitas STEMI yang dikaitkan dengan per-baikan dalam Emergency Medical Response (EMR), penerapan strategi terapi reperfusi yang efektif, dan penggunaan farmakoterapi terkait pencegahan sekunder. Angka kematian pasien STEMI di Indonesia yang mendapat terapi reperfusi secara bermakna dikatakan lebih rendah dibanding pasien yang tidak mendapat terapi reperfusi. Oleh karena itu keberhasilan dalam penerapan terapi reperfusi sangat penting untuk pasien dengan diagnosis STEMI. ${ }^{3,4}$

Infark miokard akut (IMA) merupakan sindrom klinik yang diperlihatkan dengan gejala yang ditimbulkan akibat ketidakseimbangan pasokan dan permintaan oksigen dalam darah ke jantung, perubahan elektrokardiografi (EKG) yang persisten, dan pelepasan biomarker jantung yakni creatine kinase-MB (CK-MB) atau cardiac spesific troponin (cTn)I atau (cTn)I. Ketidaknyamanan di dada tipe-iskemik seringkali menjadi gejala klinis yang paling menonjol pada pasien infark miokard, dirasakan pasien sebagai tekanan retrosternal dan sensasi terbakar yang persisten (>10 hingga 20 menit), difus, dalam, dan berat, umumnya tidak dirasakan sebagai nyeri yang menusuk. ${ }^{5}$

Infark miokard merupakan perkembangan dari otot jantung yang mengalami nekrosis akibat iskemia sebelumnya. Hal ini berkaitan dengan aterosklerosis berlanjut menghambat aliran darah dan menyebabkan terjadinya iskemia pada jaringan. ${ }^{6,7}$ Faktor risiko yang memengaruhi terbagi menjadi faktor risiko konvensional dan faktor risiko yang dapat dimodifikasi. Faktor risiko konvensional mencakup usia tua, riwayat penyakit jantung pada keluarga, dan jenis kelamin. Faktor risiko yang dapat dimodifikasi terdiri dari kadar kolesterol darah yang tinggi (low-density lipoprotein cholesterol [LDL-C]), tekanan darah yang tinggi, merokok, alkohol, diabetes melitus, obesitas, kurangnya aktivitas fisik, dan stres. ${ }^{8}$

Infark miokard akut diklasifikasikan berdasarkan hasil pemeriksaan EKG 12 sadapan menjadi ST-segment elevation myocardial infarction (STEMI) dan NonST-segment elevation myocardial infarction (NSTEMI). Penentuan klasifikasi IMA penting dalam penatalaksanaan. Tatalaksana untuk pasien STEMI yaitu dengan terapi reperfusi yang terdiri dari primary percutaneous coronary intervention (PPCI), terapi fibrinolitik, dan coronary artery bypass grafting (CABG). Penerapan PPCI dengan target $<90$ menit dari kontak medis pertama kali adalah pendekatan yang lebih dipilih di fasilitas kesehatan yang memiliki fasilitas PCI untuk pasien STEMI sesuai dengan bukti EKG dan bukti klinis lainnya. Masih banyak fasilitas kesehatan yang masih belum siap dan memiliki fasilitas PCI, sehingga terapi fibrinolitik diindikasikan untuk pasien STEMI tanpa kontraindikasi yang datang pertama kali di fasilitas kesehatan tanpa fasilitas PCI, dengan sasaran target terapi fibrinolitik adalah 30 menit. ${ }^{9,10}$ Penggunaan CABG selain untuk kasus syok kardiogenik, bukan merupakan strategi lini pertama untuk pasien STEMI. Situasi yang mengindikasikan penggunaan CABG ialah ketika kegagalan PCI, anatomi arteri koroner tidak mendukung PCI, atau perbaikan bedah yang perlu dilakukan segera. ${ }^{11}$

Kematian pasien STEMI di Indonesia yang mendapat terapi reperfusi secara bermakna dikatakan lebih rendah dibanding pasien tanpa terapi reperfusi, sehingga 
penerapan terapi reperfusi sangat penting untuk pasien dengan tujuan utama yaitu dilakukannya pemberian reperfusi yang cepat, berkelanjutan, dan tepat. ${ }^{12,13}$ Berdasarkan hal ini maka penulis terdorong untuk membahas mengenai efektivitas terapi perfusi pada infark miokard dengan STelevasi (STEMI).

\section{METODE PENELITIAN}

Penelitian ini berbentuk suatu literature review. Pencarian data menggunakan beberapa database yaitu Pubmed, Clinical Key, dan Google Scholar. Kriteria jurnal yang di review ialah artikel jurnal penelitian yang dapat diakses fulltext dalam format pdf dengan bahasa Indonesia atau Inggris atau gabungan (Indonesia dan Inggris) dengan subyek tertentu. Kata kunci yang digunakan ialah Reperfusion Therapy AND Acute Myocardial Infarction AND STEMI dan range tahun publikasi 2010-2020.

Strategi yang digunakan untuk mencari artikel penelitian yaitu menggunakan Population, Intervention, Comparison, Outcomes (PICOS). Population yang dipilih ialah pasien STEMI, dengan intervention terapi reperfusi (PPCI, terapi fibrinolitik, CABG), no camparators, dan outcomes adalah efektivitas terapi reperfusi pada pasien STEMI. Study design dan publication type yang ditelaah ialah dengan metode Quasi-experimental studies, randomized control and trial, systematic review, metaanalysis, qualitative research and crosssectional studies.

\section{HASIL PENELITIAN}

Berdasarkan hasil penelusuran setelah dilakukan beberapa tahapan, peneliti mendapatkan 3.865 jurnal yang sesuai dengan kata kunci, kemudian dilakukan skrining jurnal. Hasil pengumpulan artikel yang diperoleh dari penelusuran di setelah disaring berdasarkan kriteria-kriteria yang telah ditetapkan sebelumnya dan didapatkan 12 artikel.

Tabel 1 memperlihatkan hasil kajian 12 artikel yang dipakai dalam penelitian. Tabel 2 memperlihatkan perbandingan terapi fibrinolitik pada kajian dua artikel penelitian, sedangkan Tabel 3 memperlihatkan perbandingan PPCI vs fibrinolitik pada tiga artikel penelitian.

Tabel 1. Hasil analisis literatur penelitian

\begin{tabular}{|c|c|c|c|c|c|c|}
\hline No & Penulis & Judul & $\begin{array}{c}\text { Metode } \\
\text { penelitian }\end{array}$ & $\begin{array}{l}\text { Jumlah } \\
\text { sampel }\end{array}$ & $\begin{array}{c}\text { Jurnal } \\
\text { publikasi }\end{array}$ & Hasil dan simpulan \\
\hline 2 & $\begin{array}{l}\text { Joy et al, } \\
2016^{15}\end{array}$ & $\begin{array}{l}\text { Comparative effec- } \\
\text { tiveness of primary } \\
\text { PCI versus fibrinolytic } \\
\text { therapy for ST eleva- } \\
\text { tion myocardial inf- } \\
\text { arction: a review of } \\
\text { the literature }\end{array}$ & $\begin{array}{l}\text { Review and } \\
\text { literature } \\
\text { comparing }\end{array}$ & $\begin{array}{l}\text { 14 RCT } \\
\text { dengan } \\
10.221 \\
\text { sampel }\end{array}$ & $\begin{array}{l}\text { Journal of } \\
\text { Comparative } \\
\text { Effectiveness } \\
\text { Research }\end{array}$ & $\begin{array}{l}\text { - PPCI menjadi pilihan manajemen } \\
\text { yang disukai untuk STEMI } \\
\text { - Pemberian fibrinolitik yang dila- } \\
\text { kukan jika tindakan PCI tertunda } \\
>120 \text { menit karena waktu transfer, } \\
\text { memberikan hasil keefektifan } \\
\text { yang serupa dan merupakan pilih- } \\
\text { an yang layak } \\
\text { - Penundaan reperfusi mening- } \\
\text { katkan morbiditas dan mortalitas, } \\
\text { karena dalam satu jam pertama; }\end{array}$ \\
\hline
\end{tabular}


3

Chaiyakuna pruk et al, $2017^{16}$

4 Meta-analysis comparing primary percutaneous coronary intervention versus pharmacoinvasive therapy (PIT) in transfer patients with STelevation myocardial infarction and safety od reperfibrinolytic agents in patients with ST-segment elevation myocardial infarction: a systematic review and systematic review and
network meta-analysis $2018^{17}$ fusion therapy with

Hosseiny et al, $2016^{18}$

mortality pattern and cause of death in a long-term follow-up of patients with STEMI treated with primary PCI
6

Roule et al, $2016^{19}$
Prehospital fibrino-

lysis versus primary percutaneous coronary intervention in ST-elevation myocardial infarction: a sys-

$\begin{array}{lll}\begin{array}{l}\text { Network meta- } \\ \text { analysis based on } \\ \text { a systematic } \\ \text { review of } \\ \text { randomised } \\ \text { controlled trial }\end{array} & \begin{array}{l}40 \text { studi } \\ \text { dengan }\end{array} & \text { The Lancet } \\ & \text { sampel } & \\ & & \\ \text { Meta-analysis } & \begin{array}{l}12 \text { studi } \\ \text { dengan }\end{array} & \begin{array}{l}\text { American Journal } \\ \text { of Cardiology }\end{array}\end{array}$

Secondary data : hospital and general practice records and mortality data
1.313 sampel sampel

Open Heart setengah dari otot jantung yang awalnya berpotensi untuk diselamatkan dapat hilang, dan dalam waktu tiga jam menjadi dua pertiga bagian

- Penggunaan fibrin-spesific fibrinolitik (accelerated infusion alteplase, tenecplase, dan reteplase) dengan antikoagulan parenteral merupakan regimen yang paling efektif dan optimal karena dikaitkan dengan penurunan mortalitas jangka pendek pada pasien STEMI

- Pharmacoinvasive therapy (PIT) adalah pemberian obat trombolitik diikuti PCI segera setelah tiba di RS dengan fasilitas PCI hanya dalam kasus kegagalan trombolisis. Kegagalan trombolisis ditandai dengan gejala yang menetap 90 menit dari waktu trombolisis dan resolusi $<50 \%$ dari elevasi ST pada EKG pertama

- Pemilihan PIT dalam penelitian ini secara signifikan menurunkan angka mortalitas jangka pendek

- Terdapat risiko infark yang jauh lebih rendah pada PPCI, sedangkan risiko syok kardiogenik secara signifikan lebih tinggi.

- Laki-laki $77,5 \%$ dan perempuan $22,5 \%$

- Kelompok usia terbanyak 62,3 $\pm 13,1$ tahun

- Dalam tujuh hari pertama, terdapat risiko mortalitas yang relatif tinggi yakni 45 pasien $(3,4 \%)$ dan $76 \%$ diantaranya karena syok kardiogenik dan kegagalan multiorgan yang terkait.

- Dalam tujuh hari hingga satu tahun berikutnya, angka mortalitas mencapai 50 pasien $(3,9 \%)$ namun penyebab mortalitas yang terkait penyakit kardiovaskular didapatkan jauh lebih rendah yakni 58\%.

- Di atas 1 tahun, angka mortalitas mencapai 86 pasien $(2,05 \%)$ namun angka mortalitas terkait penyakit kardiovaskular mulai turun yakni $36 \%$, hal ini sejalan dengan peningkatan penggunaan PCI dan pengobatan evidece based

- Usia $\geq 75$ tahun, diabetes, PCI sebelumnya, syok kardiogenik, eGFR $<60$, dan pengobatan yang tertunda merupakan prediktor independen dari kematian

Systematic review and meta-analysis

6 studi Critical Care

- Penelitian ini menunjukkan bahwa terapi fibrinolitik pra-RS dibandingkan dengan PPCI memiliki tingkat kematian yang serupa 
tematic review and meta-analysis of randomized controlled trials

7 Bundhun et Bleeding events assoal, 2016 $\quad$ ciated with fibrinolytic therapy and primary percutaneous coronary intervention in patiens with STEMI

8 Cenko et al, Reperfusion therapy 2016 $\quad$ for ST-elevation acute

Systematic review
and meta-analysis
of randomized
control trials

Secondary data:
International
Survey of acute
coronary syndrom
in transitional
countries

12 studi $\quad$ Medicine
dengan
5.561
sampel

9 Granger et al, $2018^{22}$

10

Pi et al, $2017^{23}$

11 Gu et al $2010^{24}$

12 Saito et al, $2019^{25}$
Improving care of Secondarydata: STEMI in the United States 2008 to 2012 a report from the American Heart Association Mission: Lifeline Program

Utilization, hospital outcomes of coronary artery bypass grafting in patients with STsegment-elevation

\section{National}

Cardiovascular

Data Registry

Acute Coronary

Treatment and

Intervention

Outcomes

secondary data characteristic, and inmyocardial infarction myocardial infarction in Eastern Europe: the ISACS-TC Registry

57 RS

dengan 7.917

sampel

(ISACS-TC)

Network Registry

Study population /

241.244

sampel

dengan

147.466

sampel

European Heart

Journal

Journal of the American Heart Association

American Heart Association artery bypass grafting during the acute and subacute phase of STelevation myocardial infarction
1.071 sampel

Original article

Netherlands Heart Journal
- Penggunaan PPCI 49,96\% dan terapi fibrinolitik 50,06\%

- Terapi fibrinolitik jika dikaitkan dengan perdarahan intrakranial memiliki hasil yang jauh lebih tinggi dibandingkan PPCI

- Laki-laki $70 \%$ dan perempuan $30 \%$

- Penggunaan PPCI 62,4\%, terapi fibrinolitik $13 \%$, dan $24,6 \%$ pasien tidak mendapat terapi reperfusi tepat waktu

- Mortalitas pada pasien STEMI dengan PCI 5\%, terapi fibrinolitik $7,4 \%$, dan tidak mendapatkan terapi reperfusi $16 \%$

- Laki-laki 70,16\% dan perempuan $29,84 \%$

- Kelompok usia terbanyak 60 tahun

- Kualitas perawatan pasien STEMI dengan terapi reperfusi dan waktu pengobatan meningkat dalam 5 tahun

- Sebanyak $6,3 \%$ pasien STEMI menjalani CABG

- Pasien yang menjalani CABG dibagi menjadi 3 kelompok

- Kelompok (1) sebanyak 45,8\% pasien hanya menjalani CABG sebagai strategi reperfusi primer

- Kelompok (2) sebanyak 38,7\% pasien menjalani CABG setelah PPCI

- Kelompok (3) sebanyak 8,2\% pasien menjalani $\mathrm{CABG}$ setelah fibrinolitik

- Angka mortalitas pasien STEMI yang menjalani CABG adalah $5,4 \%$ dan pasien yang tidak menjalani CABG adalah 5,1\%

- Sebanyak 5,5\% pasien STEMI menjalani CABG

- Sebanyak 22\% tindakan CABG dilakukan dalam waktu 24 jam

- Sebanyak $14 \%$ tindakan CABG dilakukan antara satu dan tiga hari

- Sebanyak $64 \%$ tindakan CABG dilakukan antara empat dan 30 hari

- Tindakan CABG untuk indikasi iskemik sebanyak $31 \%$ dan untuk indikasi anatomi sebanyak $69 \%$

- Sekitar 50\% pasien STEMI mengalami multivessel disease (MVD)

- Revaskularisasi lengkap selama PPCI lebih sering dilakukan dibanding hanya pada pembuluh darah penyebab pada kasus multivessel 
- Pasien dengan revaskularisasi lengkap memiliki tingkat MACE yaitu $13 \%$ dibanding hanya pada pembuluh darah penyebab yaitu $22 \%$

Tabel 2. Perbandingan terapi fibrinolitik

\begin{tabular}{|c|c|c|c|c|c|c|c|}
\hline Jurnal & & Terapi & $\begin{array}{c}\text { Risiko } \\
\text { mortalitas } \\
\text { (Relative } \\
\text { risk) }\end{array}$ & Efektifitas & $\begin{array}{c}\text { Indikasi } \\
\text { fibrinolitik }\end{array}$ & Kontraindikasi & Komplikasi \\
\hline $\begin{array}{c}\text { Bendary et al, } \\
2017^{14}\end{array}$ & $\begin{array}{l}\text { I. } \\
\text { II. }\end{array}$ & $\begin{array}{l}\text { SK } \\
\text { accelerate } \\
\text { SK standard }\end{array}$ & $\begin{array}{l}\text { RR I }=0,5 \\
\text { RR II }=2\end{array}$ & $\begin{array}{l}\text { 31 dari } 50 \text { pasien }(62 \%) \\
\text { berhasil pada pasien } \\
\text { kelompok I } \\
19 \text { dari } 50 \text { pasien (38\%) } \\
\text { berhasil pada kelompok } \\
\text { II } \\
\text { Indikator keberhasilan : } \\
\text { i. Hilangnya nyeri } \\
\text { dada dalam } 90 \text { menit } \\
\text { setelah fibrinolitik } \\
\text { ii. Resolusi elevasi } \\
\text { segmen ST lebih } \\
\text { dari } 50 \% \text { setelah } \\
\text { fibrinolitik } \\
\text { iii. Puncak troponin I } \\
\text { jantung yang lebih } \\
\text { awal dan lebih tinggi } \\
\text { dalam } 24 \text { jam } \\
\text { pertama setelah } \\
\text { timbulnya gejala } \\
\text { iv. Kemungkinan } \\
\text { munculnya artimia } \\
\text { reperfusi }\end{array}$ & $\begin{array}{l}\text { SK merupakan } \\
\text { agen fibrinolitik } \\
\text { yang paling banyak } \\
\text { digunakan terutama } \\
\text { di negara yang } \\
\text { terbebani oleh } \\
\text { karena biaya yang } \\
\text { tinggi seperti biaya } \\
\text { tPA (alteplase) }\end{array}$ & $\begin{array}{l}\text { Severe } \\
\text { hypertension, } \\
\text { recent stroke, } \\
\text { cerebral neoplasm, } \\
\text { recent surgery, } \\
\text { childbirth, } \\
\text { hypersensitivity, } \\
\text { increased risk of } \\
\text { cerebral bleeding, } \\
\text { trauma, pregnancy, } \\
\text { active internal } \\
\text { bleeding }\end{array}$ & $\begin{array}{l}\text { Perdarahan } \\
\text { mayor }\end{array}$ \\
\hline \multirow[t]{2}{*}{$\begin{array}{c}\text { Jinatongthai et } \\
\text { al, } 2017^{16}\end{array}$} & $\begin{array}{l}\text { III. } \\
\text { IV. }\end{array}$ & $\begin{array}{l}\mathrm{TNK}+\mathrm{PAC} \\
\mathrm{rPA}+\mathrm{PAC}\end{array}$ & $\begin{array}{l}\mathrm{RR}=1.01 \\
\mathrm{RR}=1.04\end{array}$ & $\begin{array}{l}58 \% \text { pasien berhasil pada } \\
15 \text { studi yang dilaporkan } \\
\text { secara keseluruhan }\end{array}$ & $\begin{array}{ll}\text { - Secara } \\
\text { keseluruhan, } \\
\text { indikasi } \\
\text { fibrinolitik } \\
\text { diberikan jika } \\
\text { PPCI tidak } \\
\text { tersedia pada } \\
\text { RS tersebut } \\
\text { - Tindakan PCI } \\
\text { tidak dapat }\end{array}$ & $\begin{array}{l}\text { Patients at risk of } \\
\text { cerebral bleeding } \\
\text { including severe } \\
\text { hypertension, } \\
\text { history of stroke, } \\
\text { intracranial or } \\
\text { intraspinal surgery } \\
\text { or trauma within } 2 \\
\text { mth, aneurysm, } \\
\text { cerebral neoplasm, }\end{array}$ & \\
\hline & $\begin{array}{l}\text { VI. } \\
\text { VII. }\end{array}$ & $\begin{array}{l}\text { tPA + PAC } \\
\text { tPA_acc + } \\
\text { PAC }\end{array}$ & $\begin{array}{l}\mathrm{RR}=1.26 \\
\mathrm{RR}=1.00\end{array}$ & & & $\begin{array}{l}\text { Bleeding disorder, } \\
\text { severe stroke, } \\
\text { haemorrhagic } \\
\text { diasthesis, } \\
\text { intracranial and } \\
\text { subarachnoid }\end{array}$ & \\
\hline
\end{tabular}


haemorrhage,

aneurysm, history

of CNS damage,

severe HTN, major

surgery or

significant trauma

in the pas $3 \mathrm{mth}$

Keterangan : $\mathrm{SK}=$ streptokinase. $\mathrm{PAC}=$ parenteral anticoagulants. $\mathrm{rPA}=$ reteplase. $\mathrm{tPA}=$ alteplase (non-accelerated infusion $)$. $\mathrm{tPA}$ acc $=$ alteplase $($ accelerated infusion $) . \mathrm{RR}=$ relative risk/risk ratio.

Tabel 3. Perbandingan PPCI vs fibrinolitik

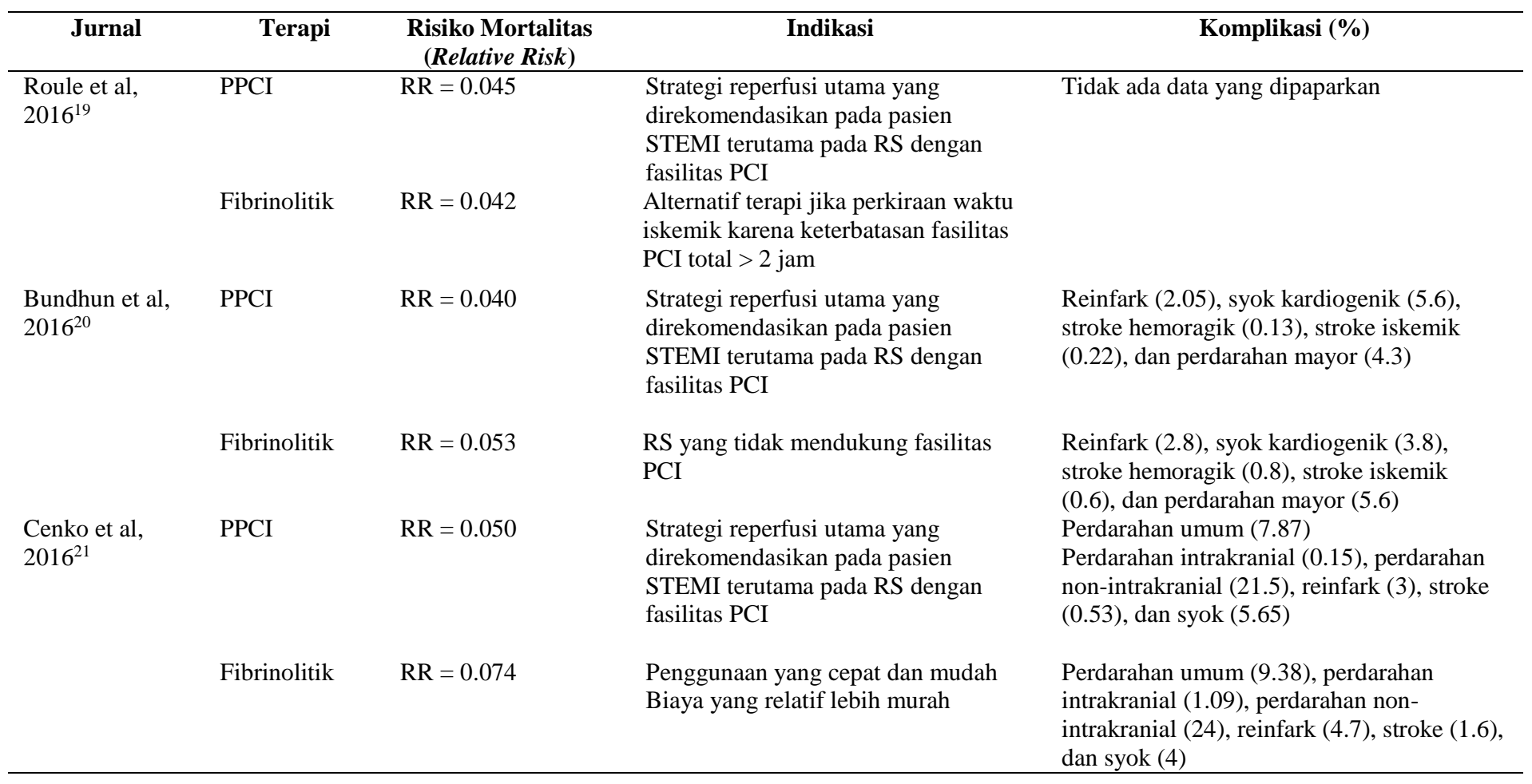

\section{BAHASAN}

Pada tahap ini telah dilakukan analisis dari beberapa penelitian yang menjelaskan tentang terapi reperfusi pada pasien STEMI. Secara keseluruhan, pasien STEMI yang mendapatkan terapi reperfusi dalam beberapa penelitian yang dilaporkan oleh Hosseiny et al, ${ }^{18}$ Cenko et al, ${ }^{21}$ Granger et al, ${ }^{22}$ didapatkan bahwa laki-laki memiliki jumlah persentase yang lebih tinggi dibandingkan perempuan dan usia rerata yang dilaporkan terkait terapi reperfusi ialah $\geq 60$ tahun (Tabel 1).

Berdasarkan penelitian yang dilakukan oleh Joy et $\mathrm{al}^{15}$ dan Cenko et al, ${ }^{21}$ dilaporkan bahwa tindakan PPCI menjadi pilihan manajemen yang lebih dipilih dan direkomendasikan untuk pasien STEMI terutama pada rumah sakit dengan fasilitas PCI yang memadai. Joy et $\mathrm{al}^{15}$ melaporkan penurunan mortalitas dan reinfark pada tindakan PPCI. Hal tersebut sesuai dalam pedoman PERKI, penggunaan PCI lebih diutamakan dan diindikasikan untuk pasien STEMI karena berpengaruh terhadap angka mortalitas. ${ }^{3,5,26}$

Penelitian Hosseiny et $\mathrm{al}^{18}$ menjelaskan mortalitas jangka panjang pada pasien STEMI sesudah penggunaan PPCI yakni dalam tujuh hari pertama terdapat risiko mortalitas yang relatif tinggi yakni 45 pasien dan $76 \%$ diantaranya karena syok kardiogenik dan kegagalan multiorgan yang terkait. Dalam tujuh hari hingga satu tahun berikutnya, angka mortalitas mencapai 50 pasien namun penyebab mortalitas yang terkait penyakit kardiovaskular didapatkan jauh lebih rendah yakni 58\%. Di atas satu tahun, angka mortalitas mencapai 86 pasien 
namun angka mortalitas terkait penyakit kardiovaskular mulai turun yakni 36\% Hal ini sejalan dengan peningkatan penggunaan PCI dan pengobatan evidence based. Penelitian ini juga melaporkan bahwa usia $\geq 75$ tahun, diabetes, PCI sebelumnya, syok kardiogenik, eGFR $<60$, dan pengobatan yang tertunda merupakan prediktor independen dari mortalitas.

Analisis penelitian Bundhun et $\mathrm{al}^{20}$ terkait komplikasi perdarahan secara umum tidak menunjukkan perbedaan bermakna. Ketika perdarahan dipaparkan terpisah, PPCI dikaitkan dengan tingkat perdarahan intrakranial yang lebih rendah dibanding fibrinolisis (Tabel 3). Setiap terapi reperfusi memiliki keunggulannya masing-masing. Terapi fibrinolitik tergolong terapi yang lebih mudah, tanpa memerlukan pembedahan, dan lebih umum di pusat kesehatan. Fibrinolisis pada penelitian ini paling efektif bila diberikan terutama dalam 60 menit pertama. $^{20,27}$

Pada penelitian Cenko et $\mathrm{al}^{21}$ dipaparkan mortalitas dalam 30 hari lebih tinggi pada kelompok fibrinolitik dibandingkan PPCI. Hal ini dikarenakan banyaknya faktor lain yang menunda pasien untuk masuk RS dan faktor ko-morbid yang memengaruhi prognosis pasien. Faktor komorbid meningkat hingga $50 \%$ pada usia mencapai 64 tahun dan $80 \%$ pada usia $>80$ tahun.

Mortalitas pasien STEMI yang dipaparkan oleh Bundhun et $\mathrm{al}^{20}$ dan Cenko et $\mathrm{al}^{21}$ secara konsisten lebih tinggi pada terapi fibrinolitik dibandingkan pada PCI yang dikaitkan dengan tingginya risiko reinfark, perdarahan mayor, dan stroke (hemoragik dan intrakranial). Penggunaan fibrinolitik untuk managemen STEMI pada penelitian Joy et $\mathrm{al},{ }^{15}$ Sidiqqi et al, ${ }^{17}$ Roule et $\mathrm{al},{ }^{19}$ dapat diberikan dalam beberapa keadaan karena memberikan hasil keefektifan yang serupa dan merupakan pilihan yang layak asalkan tidak ada kontraindikasi (Tabel 2).

Penelitian yang dilakukan oleh Jinatongthai et $\mathrm{al}^{28}$ memaparkan hasil tentang terapi fibrinolitik. Penggunaan fibrinspesific fibrinolytics (accelerated infusion alteplase, tenecplase, dan reteplase) dengan antikoagulan parenteral merupakan regimen yang paling efektif dibandingkan dengan streptokinase dan non-accelerated infusion of alteplase karena terkait mortalitas pada pasien STEMI. Pada analisis penelitian ini menjelaskan bahwa accelerated infusion alteplase yang ditambah antikoagulan parenteral merupakan standar pengobatan sesuai dengan rekomendasi pedoman yang telah ditetapkan, dalam percobaan Global Use of Strategies to Open Coronary Arteries-1 (GUSTO-1) menunjukkan terdapat penurunan angka mortalitas dalam 30 hari sebesar $15 \%$ pada pasien STEMI yang mendapat altepase dibandingkan streptokinase. ${ }^{9,26}$

Pada penelitian ini dilaporkan bahwa penggunaan streptokinase dan nonaccelerated infusion alteplase yang ditambah dengan antikoagulan parenteral dikaitkan dengan peningkatan risiko mortalitas yang bermakna (Tabel 2). Penambahan inhibitor glikoprotein IIb atau IIIa ke terapi fibrinolitik harus dihindari karena risiko perdarahan mayor yang dilaporkan lebih besar dibandinkan manfaat yang didapat. Pada penelitian Bendary et al, ${ }^{14}$ dijelaskan bahwa streptokinase diindikasikan terkait faktor ekonomi yakni biaya, hal ini sesuai dengan teori yang dijelaskan sebelumnya dalam pedoman PERKI dan CCS/CAIC bahwa streptokinase diperlihatkan dengan manfaatnya pada GISSI-1 trial dan harganya yang relatif murah. ${ }^{9,26}$

Analisis penelitian Roule et a ${ }^{19}$ (Tabel 3) menunjukkan bahwa manfaat fibrinolitik yang dilakukan pada pasien yang ditangani lebih awal yakni dua jam pertama setelah onset gejala dikaitkan dengan tingkat kematian awal dan akhir yang serupa dan peningkatan kelangsungan hidup satu tahun dibandingkan dengan penundaan PPCI. Fibrinolitik juga dikaitkan dengan angka risiko syok kardiogenik yang lebih rendah dibanding dengan penundaan satu jam pada PPCI yang mengakibatkan tingkat syok kardiogenik yang lebih tinggi.

Meningkatnya risiko perdarahan mayor pada pasien lansia menyebabkan pertimbangan penurunan dalam pemberian dosis tenekplase, hal ini juga disebutkan pada penelitian yang dilakukan oleh Jinatongthai 
et al. ${ }^{28}$ Ketetapan tersebut dilaporkan menurunkan angka kematian dan tidak ada kasus perdarahan mayor yang dilaporkan pada penelitian selanjutnya.

Fokus terkait waktu yang optimal sebagai penentu dari hasil pada pasien STEMI menyebabkan adanya perhatian pada pharmacoinvasive therapy (PIT). Tindakan PIT didefinisikan sebagai pemberian obat fibrinolitik yang diikuti PCI langsung pada kasus kegagalan fibrinolitik sesudah dilakukan pemindahan segera ke rumah sakit yang mendukung fasilitas PCI. Kegagalan fibrinolitik didefiniskan sebagai resolusi $<50 \%$ pada ST elevasi sejak EKG pertama kali atau menetapnya gejala angina selama 90 menit setelah fibrinolitik pertama. Pada penelitian Sidiqqi et al ${ }^{17}$ dilaporkan bahwa tidak ada perbedaan bermakna pada semua penyebab mortalitas antara tindakan PPCI dan PIT pada pasien yang telah di transfer.

Pendekatan PIT bermanfaat pada pasien yang diperkirakan akan menunda PPCI yang sangat lama. Penelitian Sidiqqi et a ${ }^{17}$ melaporkan bahwa PIT secara bermakna mengurangi mortalitas jangka pendek ketika waktu untuk dilakukan PPCI melebihi target. Penelitian ini juga melaporkan risiko syok kardiogenik yang secara bermakna lebih rendah pada pasien dengan PIT dibandingkan dengan PPCI. Terlepas dari manfaat tersebut, komplikasi yang timbul pada PIT sama seperti yang dilaporkan oleh Bundhun et $\mathrm{al}^{20}$ dan Cenko et $\mathrm{al}^{21}$ yakni terdapat risiko yang lebih tinggi terkait reinfark dan perdarahan mayor.

Penelitian Vogel et $\mathrm{al}^{11}$ membahas tentang strategi PCI pada kasus Multivessel Disease (MVD). Revaskularisasi lengkap selama PPCI lebih sering dilakukan dan dipilih dibanding hanya pada pembuluh darah penyebab pada kasus multivessel. Pasien yang dialokasikan untuk revaskularisasi lengkap memiliki tingkat MACE yang lebih rendah dibandingkan hanya pada pembuluh darah penyebab.

Meskipun hasil penggunaan revaskularisasi lengkap atau sebagian telah dibandingkan, masih perlu pertimbangan untuk menentukan strategi reperfusi terbaik pada kasus MVD. Beberapa ahli harus melakukan evaluasi klinis dengan mempertimbangkan karakteristik klinis pasien, tingkat keparahan penyakit, dan kondisi lesi.

Pada beberapa pasien dengan kondisi anatomi koroner yang tidak sesuai untuk PCI, CABG diindikasikan sebagai modalitas reperfusi primer pada fase akut atau setelah stabilisasi awal. Secara teori, penggunaan $\mathrm{CABG}$ merupakan salah satu terapi dengan prinsip untuk memperpanjang kelangsungan hidup dan meningkatkan kualitas hidup pasien. ${ }^{29,30}$

Indikasi lain untuk CABG meskipun tergolong jarang untuk pasien STEMI, dijelaskan dalam penelitian $\mathrm{Gu}$ et $\mathrm{al}^{24}$ dapat dilakukan sebagai pilihan jika adanya iskemia dengan salah satu dari kriteria berikut terpenuhi: iskemia persisten atau rekuren yang refrakter terhadap terapi medis, syok kardiogenik, CABG yang dilakukan bersamaan sebagai prosedur untuk ruptur septum ventrikel pasca infark atau insufisiensi katup mitral.

Mayoritas pasien yang menjalani CABG sebagai strategi reperfusi primer atau setelah PPCI, dilaporkan oleh $\mathrm{Pi}$ et $\mathrm{al}^{23}$ dilakukan dalam satu hingga tiga hari namun $\mathrm{Gu}$ et $\mathrm{al}^{24}$ melaporkan dalam empat hingga 30 hari setelah angiografi. Gu et $\mathrm{al}^{24}$ melaporkan adanya peningkatan risiko retorakotomi pada pasien STEMI yang menjalani $\mathrm{CABG}$ dalam waktu tiga hari setelah presentasi klinis. Meskipun insiden komplikasi tersebut tinggi, manajemen fase akut dan subakut dikaitkan dengan kelangsungan hidup 30 hari dan satu tahun yang sangat baik. Dalam penelitian ini juga dilaporkan angka mortalitas yang tampak rendah pada pasien STEMI yang menjalani CABG dan sebanding dengan pasien STEMI yang tidak diobati dengan CABG, hal ini menunjukkan bahwa CABG dapat dilakukan dengan aman pada pasien STEMI sesuai indikasi pada waktu yang tepat.

Penelitian Pi et al ${ }^{23}$ melaporkan faktorfaktor yang memengaruhi pasien STEMI untuk menjalani CABG berdasarkan data gambaran karakteristik klinis adalah faktor usia >60 tahun, jenis kelamin laki-laki, riwayat DM, hipertensi, dislipidemia, stroke 
sebelumnya, penyakit arteri perifer, dan fibrilasi atrium. Hal ini sesuai dengan teori terkait faktor risiko pada pasien infark miokard dibagi menjadi dua yaitu faktor risiko yang dapat dimodifikasi dan faktor risiko yang tidak dapat dimodifikasi. ${ }^{31,32}$

Keputusan dipilihnya fibrinolitik, PCI, atau CABG sebaiknya disesuaikan pada pasien yang datang ke rumah sakit tanpa fasilitas PCI dengan mempertimbangkan beberapa faktor lain yakni faktor risiko pasien, onset gejala untuk FMC, dan perkiraan waktu transfer ke RS dengan fasilitas PCI. Tindakan PPCI tetap merupakan strategi pilihan yang layak untuk pasien STEMI terutama pada RS dengan fasilitas PCI yang memadai, namun fibrinolitik yang dilanjutkan dengan PCI juga menjadi pilihan yang layak bagi pasien yang tiba pada RS tanpa fasilitas PCI yang memadai.

Secara keseluruhan kualitas perawatan untuk pasien STEMI dengan terapi reperfusi dikatakan meningkat seiring berjalannya waktu dalam 5 tahun penelitian yang dilakukan Granger et $\mathrm{al}^{22}$ terkait program Mission: Lifeline termasuk dengan peningkatan penggunaan terapi reperfusi dan waktu pengobatan yang lebih cepat, namun tetap perlu pengembangan terkait strategi pencegahan efektif dan penanganan dengan waktu yang sesuai dengan sasaran terapi untuk lebih meningkatkan hasil yang optimal.

\section{SIMPULAN}

Tindakan PCI merupakan pilihan lini pertama dan efektif diberikan dalam waktu $<120$ menit. Fibrinolitik efektif diberikan dalam 60 menit pertama bila PCI tidak dapat dilakukan. Tindakan CABG direkomendasikan pada kondisi anatomi koroner yang tidak sesuai untuk PCI dan beberapa indikasi lain, efektif dilakukan dalam empat hingga 30 hari setelah angiografi. Meskipun komplikasinya tinggi namun kelangsungan hidup 30 hari dan satu tahun sangat baik.

Disarankan pada penelitian selanjutnya untuk menggunakan data sekunder berdasarkan rekam medik agar mendapatkan data terbaru tentang pasien STEMI yang mendapatkan terapi reperfusi dari RSUP Prof. Dr. R. D. Kandou Manado atau RS di
Indonesia. Edukasi untuk masyarakat Indonesia oleh tenaga medis tentang gejalagejala STEMI terkait dengan optimalisasi waktu diagnosis, penentuan tindakan, hingga memengaruhi prognosis dan mortalitas. Diharapkan agar tetap dilakukan evaluasi terkait penatalaksanaan terapi reperfusi dan pentingnya fasilitas PCI pada fasilitas kesehatan di Indonesia.

\section{Konflik Kepentingan}

Penulis menyatakan tidak terdapat konflik kepentingan dalam studi ini.

\section{DAFTAR PUSTAKA}

1. World Health Organization. Global Health Estimates 2016: Deaths by cause, age, sex, country and region, 2000-2016. Geneva: World Health Organization, 2018.

2. Akbar H, Foth C, Kahloon RA, Mountfort S. Acute myocardial infarction ST elevation (STEMI). Stat Pearls. 2018;1-7.

3. Choudhury, Tawfiq, Nick, El-Omar M. CME cardiology ST elevation myocardial infarction. Clin Med J. 2016;16(3):27782.

4. Parung AA, Liben P, Herwanto B. Tingkat mortalitas terapi reperfusi pada penderita STEMI di RSUD Dr. Soetomo Surabaya. JUXTA. 2015;8(1):17-23. Doi: http://dx.doi.org/10.20473/ juxta.V8I12016.17-23

5. Rushton C. ST segment elevation myocardial infarction (Chapter 7). In: Humphreys M, editor. Nursing the Cardiac Patient. Wiley Online Library, 2013; p. 73-96.

6. Kumar V, Abbas AK, Aster JC. In: Ham, M, Saraswati M, editors. Buku Ajar Patologi (9th ed). 2015. p. 374-85.

7. Libby P, Buring JE, Badimon L, Hansson GK, Deanfield J, Bittencourt MS, et al. Atherosclerosis. Nat Rev Dis Prim. 2019;5(1):1-18.

8. Boudi FB, Boudi FB, Ahsan CH, Ali YS, Compton SJ, Talavera F. Risk factor for coronary artery disease. Cardiology. 2016. Available from: https:// emedicine.medscape.com/article/1641 63 -overview

9. Wong GC, Welsford M, Ainsworth C, Abuzeid W, Fordyce CB, Greene J, et al. 2019 Canadian Cardiovascular Society/ Canadian Association of Interventional 
Cardiology Guidelines on the acute management of ST-elevation myocardial infarction: focused update on regionalization and reperfusion. Can $\mathrm{J}$ Cardiol. 2019;35(2):107-32.

10. Bohula EA, Morrow DA. ST elevation myocardial infarction: management. In: Zipes D, Libby P, Bonow R, Mann D, Tomaselli G, Braunwald E, editors. Braunwald's Heart Disease: a Textbook of Cardiovascular Medicine (11th ed). Philadelphia: Elsevier Inc, 2020; p.. 1123-80.

11. Vogel B, Claessen BE, Arnold S V., Chan D, Cohen DJ, Giannitsis E, et al. STsegment elevation myocardial infarction. Nat Rev. 2019;5(1):1-20.

12. Dharma S, Rahajoe A, Soerianata S. Jakarta Cardiovascular care unit network system. Indones J Cardiol. 2012;33(2): 106-12. Available from: https://doi. org/10.30701/ijc.v33i2.61.

13. Menozzi A. An Overview on STEMI. Minerva Cardioangiol. 2018;66(4):391.

14. Bendary A, Tawfik W, Mahrous M, Salem M. Fibrinolytic therapy in patients with STsegment elevation myocardial infarction: accelerated versus standard streptokinase infusion regimen. J Cardiovasc Thorac Res. 2017;9(4):209-14.

15. Joy ER, Kurian J, Gale CP. Comparative effectiveness of primary PCI versus fibrinolytic therapy for ST elevation myocardial infarction: a review of the literature. J Comp Eff Res. 2016;5(2): 217-26.

16. Jinatongthai P, Kongwatcharapong J, Foo CY, Phrommintikul A, Nathisuwan S, Thakkinstian A, et al. Comparative efficacy and safety of reperfusion therapy with fibrino-lytic agents in patients with STsegment elevation myocardial infarction: a systematic review and network meta-analysis. Lancet. 2017;390 (10096):747-59.

17. Siddiqi TJ, Usman MS, Khan MS, Sreenivasan JK, Kassas I, Riaz H, et al. Metaanalysis comparing primary percutaneous coronary intervention versus pharmacoinvasive therapy in transfer patients with ST-elevation myocardial infarction. Am J Cardiol. 2018;122(4): 542-7.

18. Hosseiny DA, Moloi S, Chandrasekhar J, Farshid A. Mortality pattern and cause of death in a long-term follow-up of patients with STEMI treated with primary PCI. Open Heart. 2016;3(1): e000405.

19. Roule V, Ardouin P, Blanchart K, Lemaitre A, Wain-Hobson J, Legallois D, et al. Prehospital fibrinolysis versus primary percutaneous coronary intervention in ST-elevation myocardial infarction: a systematic review and meta-analysis of randomized controlled trials. Crit Care. 2016;20(1):1-7.

20. Bundhun PK, Janoo G, Chen M-H. Bleeding events associated with fibrinolytic therapy and primary percutaneous coronary intervention in patients with STEMI. Medicine (Baltimore). 2016;95(23): e3877.

21. Cenko E, Ricci B, Kedev S, Vasiljevic Z, Dorobantu M, Gustiene O, et al. Reperfusion therapy for ST-elevation acute myocardial infarction in Eastern Europe: The ISACS-TC registry. Eur Hear J-Qual Care Clin Outcomes. 2016;2(1):45-51.

22. Granger CB, Bates ER, Jollis JG, Antman EM, Nichol G, O'connor RE, et al. Improving Care of STEMI in the United States 2008 to 2012 A Report from The American Heart Association Mission: Lifeline Program. J Am Heart Assoc. 2019;8(1):1-8.

23. Pi Y, Roe MT, Holmes DN, Chiswell K, Garvey JL, Fonarow GC, et al. Utilization, characteristics, and inhospital outcomes of coronary artery bypass grafting in patients with STsegment-elevation myocardial infarction: results from the National Cardiovascular Data Registry Acute Coronary Treatment and Intervention Outcome. Circ Cardiovasc Qual Outcomes. 2017; 10(8):1-8.

24. Gu YL, Van der Horst ICC, Douglas YL, Svilaas T, Mariani MA, Zijlstra F. Role of coronary artery bypass grafting during the acute and subacute phase of STelevation myocardial infarction. Netherlands Heart J. 2010;18(7):348-54.

25. Saito Y, Kobayashi Y. Percutaneous coronary intervention strategies in patients with acute myocardial infarction and multivessel disease: completeness, timing, lesion assessment, and patient status. J Cardiol. 2019;74(2):95-101. 
26. Juzar DA, Danny SS, Irmalita, Tobing DPL, Firdaus I, Widyantoro B, et al. Pedoman Tatalaksana Sindrom Koroner Akut (4th ed). Jakarta: Perhimpunan Dokter Spesialis Kardiovaskular Indonesia, 2018; p. 76 .

27. Sudoyo AW, Setiyohadi B, Alwi I, Simadibrata M, Setiadi S. Buku Ajar Ilmu Penyakit Dalam (6th ed). Jakarta: Interna Publishing, 2014.

28. Jinatongthai $\mathrm{P}$, Kongwatcharapong J, Foo CY, Phrommintikul A, Nathisuwan S, Thakkinstian A, et al. Comparative efficacy and safety of reperfusion therapy with fibrinolytic agents in patients with STsegment elevation myocardial infarction: a systematic review and network meta-analysis. Lancet. 2017;390(10096): 747-59. Available from: http://dx.doi. org/10.1016/S0140-6736(17)31441-1

29. Harrington DH, Stueben F, Lenahan CMD.
ST-elevation myocardial infarction and non-ST-elevation myocardial infarction: medical and surgical interventions. Crit Care Nurs Clin North Am. 2019;31(1): 49-64.

30. Khan MS, Islam MYU, Ahmed MU, Bawany FI, Khan A, Arshad MH. On pump coronary artery bypass graft surgery versus off pump coronary artery bypass graft surgery: a review. Glob J Health Sci. 2014;6(3):186-93.

31. Depkes RI. Profil Kesehatan Indonesia. Jakarta: Kementerian Kesehatan Republik Indonesia, 2018; p.1. Available from: https://pusdatin.kemkes.go.id/ resources/download/pusdatin/profil-kes ehatan-indonesia/PROFIL KESEHATAN_2018_1.pdf

32. Rathore V. Risk factors of acute myocardial infarction: a review. Eurasian J Med Investig. 2018;2(1):1-7. 